\title{
AVALIAÇÃO DE DICIONÁRIOS INFANTIS ILUSTRADOS PARA O ENSINO DE ESPANHOL COMO LÍNGUA ESTRANGEIRA
}

\author{
EVALUACIÓN DE DICCIONARIOS INFANTILES ILUSTRADOS PARA LA \\ ENSEÑANZA DE ESPAÑOL COMO LENGUA EXTRANJERA
}

\section{Renata Martins da Silva ${ }^{1}$}

Resumo: Apresenta-se aqui uma análise de dicionários infantis ilustrados de espanhol direcionados a crianças brasileiras de seis anos, visto que o professor deste público carece de um panorama que lhe indique quais dicionários podem ser utilizados e como empregá-los. $\mathrm{O}$ trabalho tem como objetivos proporcionar-lhes um entendimento mais amplo dessa classe de dicionários e identificar qual é, entre os avaliados, o mais adequado. Os resultados comprovam que i) há uma carência de materiais direcionados a este público e que ii) os dicionários existentes não atendem totalmente às possíveis demandas dos consulentes, embora apresentem melhorias conforme suas datas de publicação.

Palavras-chave: dicionários ilustrados; espanhol como língua estrangeira; crianças.

Resumen: Se presenta aquí un análisis de diccionarios infantiles ilustrados de español direccionados a niños brasileños de seis años, ya que el profesor de ese público carece de un panorama que le indique cuáles diccionarios se pueden utilizar y cómo emplearlos. El trabajo tiene como objetivos proporcionarles una comprensión más amplia de esa clase de diccionarios e identificar cuál es, entre los evaluados, el más adecuado. Los resultados comprueban que i) existe una carencia de materiales direccionados a este público; ii) los diccionarios existentes no atienden totalmente a las posibles demandas del usuario, aunque presenten mejorías conforme sus fechas de publicación.

Palabras- clave: diccionarios ilustrados; español como lengua extranjera; niños.

\section{Introdução}

Há, no mercado editorial, uma classe de dicionários que almeja auxiliar na primeira etapa do ensino e aprendizagem de espanhol como língua estrangeira (ELE) para crianças. Poucos são, no entanto, os dicionários que são pensados e voltados a um público mais específico, como, por exemplo, crianças brasileiras em processo de alfabetização. Sabe-se que não é uma tarefa fácil pensar em materiais para esse público específico, visto que não há orientações pedagógicas ao docente para o trabalho com esta faixa etária. De acordo com

\footnotetext{
${ }^{1}$ Mestranda na área de Lexicografia do Instituto de Letras da Universidade Federal do Rio Grande do Sul (UFRGS). Bolsista do Conselho Nacional de Desenvolvimento Científico e Tecnológico (CNPq). E-mail: renata.martins@ufrgs.br
} 
Chaguri (2013), um dos problemas emergentes do contexto de ensino de línguas estrangeiras (LE) nas séries iniciais do Ensino Fundamental é justamente a precariedade em se adquirir e contar com materiais didáticos e / ou livros adequados a esse ensino conforme a necessidade e situação de ensino do aluno da rede escolar (p. 114).

Analisando os materiais existentes, percebe-se que "a ideia da produção de um material único para todos pode ser interessante do ponto de vista de uma economia de escala (...), mas pode não atender as necessidades específicas de muitos alunos" (LEFFA; IRALA, 2014, p. 40 e 41). Em virtude da escassa produção de dicionários de ELE elaborados para este público específico, acredita-se ser de suma importância uma análise dos poucos materiais existentes que podem ser utilizados com crianças brasileiras em processo de alfabetização para que se possa ter, assim, um melhor aproveitamento dos mesmos em sala de aula, pensando quais e como podem ser utilizados considerando as capacidades cognitivas que possuem os aprendizes desse nível de escolaridade e dessa faixa etária. Ao realizar essa análise, visa-se também proporcionar aos educadores um entendimento mais amplo deste material, assim como do perfil do seu aluno. Em virtude do exposto, o presente trabalho se propõe a realizar as análises de três dicionários infantis ilustrados para o ensino de ELE para crianças.

Ao fazer-se essa avaliação dos materiais, foram consideradas características do público infantil abordadas por diferentes autores, como, por exemplo, López e Méndez (2004). Além disso, julgou-se necessário elaborar um modelo de metodologia de análise no que diz respeito à macroestrutura dos dicionários, visto que não há nenhum padrão disponível para ser utilizado como parâmetro nas análises. Para isso, portanto, compilou-se o léxico de um livro didático direcionado ao ensino de espanhol para este público. Essa compilação léxica corresponde à macroestrutura que esses dicionários deveriam ter. É relevante mencionar que não é possível ter um padrão de análise totalmente eficiente ao compilar um corpus a partir do léxico de apenas um livro didático, evidentemente. O corpus aqui compilado serve, portanto, fundamentalmente como um teste de metodologia e, em virtude disso, tornar-se-ia necessário expandi-lo com uma compilação do léxico de uma quantidade mais significativa de materiais para criar uma base de análise mais eficiente. Antes de iniciar as análises, será feito um levantamento das características do usuário e dos dicionários em geral para esse público. Em seguida serão expostas as análises e conclusões. 


\section{Características do público-alvo}

Diversos autores afirmam que há muitas vantagens em dar início ao ensino de línguas estrangeiras na infância (Rocha, 2006 e 2007; Brewster, Ellis \& Girard, 2002; Ellis, 2004; Cameron, 2001; Ruiz, 2014; entre outros). Rocha (2006) vincula uma das vantagens a um melhor desempenho da criança em séries posteriores, ressaltando a relação do ensino de línguas estrangeiras com o desenvolvimento psicológico, físico, afetivo e sociocultural do aprendiz, além de seu desenvolvimento linguístico (p. 68), o que vai totalmente ao encontro das ideias de Ruiz (2014), que afirma que, ao iniciar desde cedo seu aprendizado de línguas, as crianças dispõem de mais tempo para assimilação e adquirem uma experiência linguística e cultural que pode beneficiar seu desenvolvimento em geral, seja este cognitivo, social, cultural, acústico, linguístico ou pessoal. Ellis (2004, apud ROCHA, 2007) também afirma que a criança possui diversas características que favorecem a aprendizagem de uma língua estrangeira (LE), tais como a espontaneidade, curiosidade e desinibição, sendo esse outro motivo para se defender o início desse ensino na infância.

De acordo com López e Méndez (2004, p. 168), no que tange o desenvolvimento da criança quanto à aquisição da linguagem, aprendizes com seis anos completos já são capazes de ler e escrever ${ }^{2}$, podendo, portanto, começar com seu processo de alfabetização. Esses aspectos do desenvolvimento infantil podem ser vistos na Tabela 01, na coluna denominada pelas autoras de Language Acquisition:

Tabela 01: Tabela de desenvolvimento infantil.

\begin{tabular}{|c|c|c|c|}
\hline Age & Body Coordination & Language Acquisition & $\begin{array}{l}\text { Individual Features } \\
\text { and Intelligence }\end{array}$ \\
\hline $5-6$ & $\begin{array}{l}\text { - They can catch a bounced } \\
\text { ball at waist level. } \\
\text { - They can run } 30 \mathrm{~m} \text { in } 10 \\
\text { seconds. } \\
\text { - They can catch a ball with } \\
\text { elbows tucked in. }\end{array}$ & $\begin{array}{l}\text { - They use grammar almost } \\
\text { correctly. } \\
\text { - They start reading and } \\
\text { writing. }\end{array}$ & $\begin{array}{l}\text { - Children imitate adult's } \\
\text { behaviors. } \\
\text { - Relationships with } \\
\text { classmates and friends are } \\
\text { more and more important. }\end{array}$ \\
\hline $6-7$ & $\begin{array}{l}\text { - They can draw squares, } \\
\text { rectangles, triangles, oblongs, } \\
\text { diamonds. } \\
\text { - They can walk in a straight } \\
\text { line. }\end{array}$ & $\begin{array}{l}\text { - They do not make any } \\
\text { mistakes with grammar. } \\
\text { - They can read and write. }\end{array}$ & $\begin{array}{l}\text { - They admire teachers } \\
\text { and parents. } \\
\text { - They can work very well } \\
\text { in groups. }\end{array}$ \\
\hline
\end{tabular}

FONTE: LÓPEZ e MÉNDEZ (2004).

Além da teoria psicológica, deve-se considerar a legislação brasileira, na qual é possível identificar, de acordo com o artigo 32 da seção III da LDB de 1996, que o ensino fundamental

\footnotetext{
${ }^{2}$ [They can read and write].
} 
passa a ser obrigatório à criança aos seus seis anos de idade, sendo nessa etapa o início do processo de alfabetização. Analisando-se, portanto, tanto o que diz a teoria a respeito das capacidades cognitivas relacionadas à etapa de desenvolvimento na qual o estudante se encontra quanto o estabelecido pela legislação brasileira, pode-se concluir que o público de seis anos de idade é um público que ainda não se encontra alfabetizado, visto que os aprendizes recém estão aptos a iniciar o processo de alfabetização nesta idade. Pensando-se nas quatro competências linguísticas - "escuta, fala, leitura e escrita"3 (DLTApL, 2002, s.v, language skills) - da abordagem comunicativa para o ensino de línguas estrangeiras do Marco Comum Europeu de Referência $^{4}$ (MCER, 2002), pode-se afirmar que estudantes de seis anos de idade possuem apenas as destrezas de fala e escuta desenvolvidas em virtude de se encontrarem no início do processo de alfabetização, não estando aptos ainda, portanto, a atividades e ao uso de materiais que envolvam as destrezas de leitura e escrita.

\section{Dicionários infantis}

Após alguns levantamentos das características do público-alvo e antes de dar início às análises per se dos dicionários, julga-se necessário aclarar alguns pontos gerais sobre esse material. Primeiramente, pode-se dizer que os dicionários possuem alguns parâmetros preestabelecidos: a macroestrutura, a microestrutura, o "Front Matter" e o usuário, sendo os três primeiros seus componentes canônicos (BORBA; BUGUEÑO MIRANDA, 2012). É importante analisar como se organizam esses componentes canônicos nos dicionários em questão para que se possa pensar nas suas possibilidades de uso. Também julga-se relevante, ao selecionar esse material para análise, que se estabeleçam os princípios de cada parâmetro para que se possa classificar os dicionários, tarefa de suma importância a) para o compilador, que poderá desenhar um instrumento de consulta segundo um conjunto de padrões e parâmetros formais que podem garantir sua real utilidade; b) para o usuário, que terá um panorama das obras disponíveis e poderá fazer uma escolha mais acertada segundo suas necessidades e c) para o crítico, que terá um subsídio que o ajudará na tarefa avaliadora das obras lexicográficas (BUGUEÑO MIRANDA, 2013), como no caso deste trabalho, que terá esse papel de avaliação crítica das obras selecionadas.

\footnotetext{
${ }^{3}$ [Listening, speaking, reading, and writing].

${ }^{4}$ Disponível em: <http://cvc.cervantes.es/ensenanza/biblioteca_ele/marco/cvc_mer.pdf>. Acesso em: 19 agosto 2017.
} 


\subsection{Macroestrutura}

A macroestrutura é o conjunto de entradas geralmente ordenadas de maneira vertical no dicionário. De acordo com Gouws (2003), "no planejamento de um novo dicionário, deve-se dar atenção às diferentes estratégias e procedimentos macroestruturais a serem aplicados"5 (p. 39). Bugueño Miranda (2013) expõe que a constituição de uma macroestrutura passa por uma seleção quantitativa e qualitativa. A definição macroestrutural quantitativa diz respeito à quantidade de lemas que um dicionário deve possuir; em virtude de não haver, porém, um número de lemas definido para a macroestrutura de um dicionário, essa delimitação quantitativa apresenta uma problemática na elaboração macroestrutural desse material. Sobre isso, Biderman (1998, p. 131) aponta:

O primeiro problema que se põe na elaboração de um dicionário é a extensão da sua nomenclatura e/ou macroestrutura. $\mathrm{O}$ tamanho desse índice de palavras é fator de algumas coordenadas: em primeiro lugar, o público a que se destina. Tal será o destinatário desejado, tal o numerário.

Ainda que não se saiba, portanto, o número exato de entradas que um dicionário deve possuir, sabe-se que essa quantidade vai depender do público ao qual o dicionário será desenhado. No caso dos dicionários ilustrados para o público-alvo deste trabalho, seria possível fazer um cálculo aproximado dessa macroestrutura a partir da análise dos livros didáticos destinados a esses alunos.

Em relação à definição da macroestrutura qualitativa, pode-se relacioná-la a escolha dos lemas. Bugueño Miranda (op.cit) afirma que os dicionários, em geral, podem catalogar toda classe de curiosidades, sejam elas estritamente linguísticas ou não - como, por exemplo, fórmulas ou siglas. Deve-se pensar, no entanto, o que cabe catalogar em cada classe de dicionário e, mais especificamente, o que deve ser catalogado na classe de dicionários aqui analisada.

A definição desses parâmetros torna-se algo necessário, visto que um dicionário não pode dar conta de todo o léxico de uma língua. "O objetivo final é chegar a uma macroestrutura eficiente, $[. .$.$] que seja coerente com a classe de dicionário de que se trata, coerente com a função$

\footnotetext{
${ }^{5}$ [in the planning of a new dictionary attention has to be given to the different macroestrutural strategies and procedures to be applied in the dictionary]
} 
conferida ao dicionário, e que satisfaça também as demandas do usuário" (ibidem, p. 24). Cabe questionar como deve ser a seleção macroestrutural em um dicionário infantil ilustrado para o ensino de ELE para o público-alvo deste trabalho.

Ao pensar-se nos princípios de definição macroestrutural quantitativa e qualitativa para um dicionário voltado para o público infantil em fase de pré-alfabetização e que estejam aprendendo uma língua estrangeira, defende-se que a macroestrutura quantitativa não deve ser excessiva para não gerar uma saturação quanto à quantidade de lemas, já que o educando/usuário de 6-7 anos de idade utilizará o material primordialmente para consultar o léxico dos conteúdos aprendidos no primeiro ano de ensino-aprendizagem do idioma. Quanto à macroestrutura qualitativa do dicionário para nosso potencial usuário, defende-se que seja feita uma escolha entre os lemas presentes no léxico dos livros didáticos direcionados à essa idade, tais como vocabulário de família e de comida, por exemplo, que são trabalhados com esta faixa etária.

Para verificar se os dicionários que serão analisados aqui cumprem ou não com esses princípios de definição macroestrutural, será utilizado o volume 1 do Livro Didático Clan 7 con ¡Hola, amigos! como base para um levantamento do léxico aprendido por alunos que tenham entre seis e sete anos e estejam começando a aprender espanhol. Uma das razões para a escolha desse livro didático se dá por haver, se comparado a outros, uma maior facilidade na sua aquisição devido sua disponibilidade para compra nas lojas físicas e até mesmo online de livrarias como Saraiva, SBS, Disal, Cultura, entre outras (realizando-se a procura nesses sites, encontra-se o material com o status de "item disponível")"; além disso - e não menos importante -, destaca-se o fato de ser um dos poucos livros que se propõe a trabalhar com o público-alvo deste trabalho, visto que a maioria dos materiais didáticos está dirigida a crianças maiores de 8 anos de idade (e em alguns casos, mas não com a mesma frequência, maiores de 7 anos de idade $^{7}$ ) haja vista que, nesta idade, os alunos geralmente já estão alfabetizados. Mais raros são os casos onde encontramos, portanto, materiais destinados a educandos de 6 anos de idade em virtude do processo alfabetização, que nesta idade está apenas começando.

\footnotetext{
6 Para realizar a busca online, basta acessar sites como o da livraria Disal (acesso pelo link $<$ https://www.disal.com.br/produto/2369842-clan-7-con-hola-amigos-1-libro-del-al>), por exemplo, e digitar o nome do livro didático desejado.

${ }^{7}$ Um exemplo deste caso seria o material Mi mundo en palabras, elaborado para alunos de 7 a 9 anos pelo Instituto Cervantes para uso nos seus cursos de espanhol para crianças. Tal informação pode ser acessada em: <https://portoalegre.cervantes.es/br/cursos_portugues/estudantes_portugues/cursos_criancas_portugues.htm>. Acesso em: 09 out. 2018.
} 
Em virtude de o primeiro volume do livro ser direcionado ao público de seis anos, utilizou-se esse volume para organizar a tabela a seguir com a compilação do léxico desta etapa do curso de ELE. É importante reiterar que o livro referido será usado apenas como um modelo para testar o procedimento de análise dos dicionários e que, para uma metodologia mais precisa, seria necessário ampliar esse corpus a partir da compilação do léxico presente em outros livros direcionados a esse público.

Quadro 01: Quadro-base para análise macroestrutural dos dicionários infantis.

\begin{tabular}{|c|c|}
\hline UNIDAD & VOCABULARIO \\
\hline 1 - ¡Hola, amigos! & $\begin{array}{l}\text { - } \quad \text { Números del } 1 \text { al 10; } \\
\text { - } \quad \text { Rojo, amarillo, azul, verde, blanco, negro. }\end{array}$ \\
\hline 2 - Te presento a mi familia & $\begin{array}{l}\text { - } \quad \text { Mamá, papá, hermano/-a, tío/-a, abuelo/-a, amigo. } \\
\text { - } \quad \text { Bibliotecario/-a, profesor/-a, alumno/-a, director/-a, } \\
\text { cocinero/-a, médico/-a, abogado/-a, conductor/-a. }\end{array}$ \\
\hline 3 - ¡El martes tenemos español! & $-/-$ \\
\hline $\begin{array}{l}4 \text { - ¡Mmm... Me gusta el } \\
\text { helado! }\end{array}$ & $\begin{array}{l}\text { - Pollo, queso, pescado, patatas, huevos, arroz, manzanas, } \\
\text { zumo, naranjas, tomates, helado, pan. } \\
\text { - } \quad \text { Frigorífico. } \\
\text { - Leche, tostada. }\end{array}$ \\
\hline $\begin{array}{l}5-¿ \text { Me prestas tu goma, por } \\
\text { favor? }\end{array}$ & $\begin{array}{l}\text { - Lápiz, goma, sacapuntas, cuaderno, libro, lápices de } \\
\text { colores, mochila, regla, tijeras, bolígrafo, pegamento, } \\
\text { ordenador. } \\
\text { - Clase, pupitres, estanterías, pizarra. } \\
\text { - } \quad \text { Ventana, casa, papelera. }\end{array}$ \\
\hline 6 - ¿Dónde está el caballo? & $\begin{array}{l}\text { Perro, caballo, oveja, vaca, pato, burro, gallina, cerdo; } \\
\text { árbol, establo, estanque, granero; }\end{array}$ \\
\hline 7 - ¡Jugamos en el jardín! & $\begin{array}{l}\text { - Habitación/dormitorio, cuarto de baño, salón, cocina, } \\
\text { garaje, jardín, cama, espejo, bañera, mesa, silla, sofá, } \\
\text { televisor, horno, coche, columpio, casa. } \\
\text { - Pelota/balón, escondite, rayuela. } \\
\text { - Cartas, cometa. }\end{array}$ \\
\hline 8 - ¡Qué boca más grande! & - $\quad$ Cuerpo, pelo, ojo, nariz, boca, oreja, mano, pie, payaso. \\
\hline 9 - ¡Vacaciones! & $\begin{array}{l}\text { - Primavera, verano, otoño, invierno, viento, sol, llueve } \\
\text { (ler lluvia), nieva (ler nieve). } \\
\text { - Río, bocadillo, flores, hojas. }\end{array}$ \\
\hline
\end{tabular}

Fonte: Elaboração da autora, Porto Alegre, 2018. 
Ao realizar-se a análise do léxico do livro didático, considerou-se importante verificar quais palavras encontradas de fato poderiam ser lematizadas em um dicionário ilustrado antes da elaboração do quadro. Julgou-se relevante eliminar do corpus, por exemplo, todos os verbos, visto que, de acordo com CamDic (2017, s.v. verb) significa "uma palavra ou um grupo de

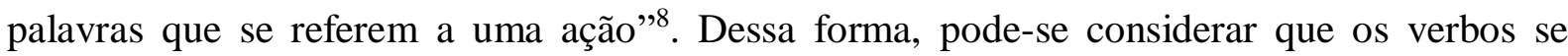
enquadram em uma classe de palavras que não pode ser representada pelas figuras estáticas dos dicionários por imagem pelo fato de representarem algo que se encontra em movimento/ação e produzirem, neste tipo de representação por figuras, uma confusão de sentido no entendimento dos possíveis usuários (quando há uma figura representando o verbo abraçar, por exemplo, o consulente pode bem entender que a representação significa "cumprimentar", "felicitar", entre outros significados possíveis na representação de um abraço).

Bugueño Miranda (2004/2005), ao abordar quais são os pontos da constituição da macroestrutura no dicionário de língua, afirma que, na tradição de Cobuild (1995), um dos critérios da seleção macroestrutural quantitativa seria o critério estatístico:

\section{Para tal efeito, estabelece-se uma escala de frequência de unidades léxicas e calcula- se um número mínimo de ocorrências. Uma frequência menor ao número mínimo de ocorrências implica que essa unidade léxica não aparecerá na nominata do dicionário (BUGUEÑO MIRANDA, 2004/2005, p. 21)}

A partir desse critério, eliminou-se do quadro do léxico do livro didático algumas unidades léxicas pouco utilizadas em países falantes de espanhol. Cabe questionar aqui qual seria, portanto, o número mínimo de ocorrências estabelecido para o critério estatístico. Faz-se importante mencionar que não existe um critério absoluto para essa definição de ocorrências mínimas, porém pode-se utilizar (da mesma forma que se fará aqui) um critério de comparação. Para estabelecer um número mínimo a partir do critério comparativo, verificou-se, utilizando o Corpus de Referencia del Español Actual (CREA) ${ }^{9}$, qual é o número de ocorrências do corpus de palavras mais frequentes para que se pudesse comparar com as ocorrências do léxico do livro didático e, dessa forma, definir quais unidades léxicas deveriam ser eliminadas do quadro.

De acordo com as informações disponíveis no CREA, o substantivo com o maior número de ocorrências é años, que é encontrado 214 mil vezes no corpus. Ao pesquisar, por exemplo, as ocorrências da palavra oca, encontra-se apenas 149 ocorrências, sendo mais de 100

\footnotetext{
${ }^{8}$ [a word or group of words that refers to an action].

${ }^{9}$ O CREA está composto por textos escritos e orais produzidos em todos os países de língua espanhola entre 1975 e 2004. O CREA permite verificar o número exato de ocorrências e em quais países foi encontrada cada ocorrência. Disponível em: < http://corpus.rae.es/creanet.html>. Acesso em: 24 out 2017.
} 
dessas ocorrências registros provenientes da Espanha. Em virtude de oca aparecer, em média, 1430 vezes menos que años e ser uma palavra com o maior número de ocorrências em apenas um país, considerou-se que essa palavra não deve ser dicionarizada. Para definir, então, quais palavras poderiam entrar no quadro a partir do critério estatístico comparativo, estipulou-se que, para serem incluídas, as palavras precisam aparecer, no mínimo, 214 vezes, ou seja, ter, no máximo, mil vezes menos ocorrências que a palavra que mais apareceu (palavra años, com 214 mil registros). Além disso, estipulou-se que a palavra não pode ter mais de $50 \%$ de suas ocorrências em apenas um país falante do idioma. A partir desses critérios, foram eliminadas palavras como peonza e comba, por exemplo.

\subsection{Microestrutura}

Após a definição de alguns parâmetros para investigar a quantidade de lemas (macroestrutura quantitativa) e a escolha dos lemas (macroestrutura qualitativa) que devem constar em um dicionário infantil ilustrado, julga-se necessário averiguar também a respeito das informações que são apresentadas sobre cada lema. Essas informações sobre cada lema são chamadas de microestrutura. De acordo com Bugueño Miranda (2008), a microestrutura é o conjunto de informações referentes ao signo-lema e, pelas definições de Wiegand (1989, apud BUGUEÑO MIRANDA, 2008), na qual se deve reconhecer dois blocos que atendem à concepção saussureana do signo linguístico: informações do signo-lema enquanto significante, que neste caso os autores chamam de "comentário de forma", e enquanto significado, que é chamado de "comentário semântico" (BUGUEÑO MIRANDA, 2008, p. 6). No que se refere especificamente à microestrutura de um dicionário infantil ilustrado para um público em processo de alfabetização, pode-se aferir que, por se tratar de um usuário que ainda não possui a habilidade de leitura desenvolvida, as definições para os lemas tornam-se pouco relevantes. Sendo as imagens a macroestrutura de um dicionário ilustrado, sua microestrutura passa a ser, portanto, a forma gráfica da palavra - o comentário de forma. Com isso, pode-se afirmar que um dicionário ilustrado que se destine ao público que ainda se encontra no início do seu processo de alfabetização possui, na sua microestrutura, informações do signo-lema especificamente enquanto seu significante, ou seja, a representação ortográfica.

\subsection{O usuário}


Não podendo abranger todo o léxico de uma língua, o dicionário deve ser concebido com objetivos e público-alvo específicos. Esse é denominado por Weigand (1977, apud BUGUEÑO MIRANDA, 2008) como o “ilustre desconhecido". É preciso perguntar-se que tipo de informações o usuário espera encontrar e que tipo de informações o dicionário efetivamente deve oferecer. Ao pensar-se no desenho de dicionários para alunos de seis a sete anos de idade e que estudam espanhol como língua estrangeira, cabe questionar que tipo de informação tal consulente busca encontrar nesta classe de material. Pode-se aferir que um aluno nesta faixa etária recorre ao dicionário para aprender designações, porquanto já possui as destrezas de compreensão auditiva e expressão oral desenvolvidas. Não é adequado, portanto, sobrecarregar os lemas com excesso de informações que não são relevantes ao educando, já que a função do dicionário é dar uma resposta imediata às dúvidas que o usuário objetiva esclarecer.

\subsection{O Front Matter}

O Front Matter, que deve ser encontrado no início de um dicionário, apresenta as informações do material ao consulente. Para que um Front Matter seja eficiente, ele deve cumprir com dois requisitos: 1 . Para que e para quem o material se destina; 2 . Como o dicionário pode ser utilizado, servindo, podemos dizer, como um manual de instruções (BUGUEÑO MIRANDA, 2016).

\section{Análises dos dicionários infantis ilustrados}

A seguir, serão expostas as análises que foram realizadas dos três dicionários infantis ilustrados de ELE. Optou-se por analisar dicionários impressos devido à escassez de dicionários ilustrados direcionados a esse público no meio digital. A ordem das análises se dará pela cronologia das publicações dos dicionários. Nas análises, foram levados em conta os componentes canônicos mencionados anteriormente: a macroestrutura (que será analisada a partir do quadro elaborado com o léxico do livro didático já exposto), a microestrutura e o Front Matter. Todos esses componentes foram analisados em relação ao público-alvo, crianças brasileiras de seis anos de idade. 


\subsection{Análise 1: Pictodiccionario (1995)}

Ao se fazer uma análise da obra Pictodiccionario (1995) (doravante PictoD (1995)), encontra-se, na sua macroestrutura, 85 lemas em comum às palavras do quadro elaborado a partir do livro didático. No total, esse dicionário possui mais de 1500 lemas organizados por temas. Mais de 1400 lemas presentes na obra, portanto, não fazem parte do léxico que, de acordo com o quadro utilizado na análise, pertence a este nível do curso de ELE para crianças. Com isso, pode-se afirmar que este dicionário possui um inchaço macroestrutural, visto que, pensando-se em todas as palavras do PictoD (1995), os 85 lemas que são comuns ao quadro do livro representam apenas $5,66 \%$ de toda a macroestrutura do dicionário.

Analisando a macroestrutura qualitativa da obra, ou seja, a escolha dos seus lemas, podese considerá-la inadequada ao público, porquanto identifica-se que nela constam inúmeras palavras que não fazem parte do cotidiano infantil, tais como vocábulos relacionados a equipamentos de jardinagem ou aos mais diversos tipos de flores - petunia, hortensia, lirio, dalia, tulipa, por exemplo. De acordo com os PCN (1997), as Ciências Naturais já estão, de fato, presentes no primeiro ciclo do Ensino Fundamental, contudo o documento especifica claramente que, nesta etapa, animais e plantas devem ser abordados para a compreensão do ciclo vital - nascer, crescer, reproduzir e morrer - sem a exigência da utilização da nomenclatura (p. 48). Assim sendo, considera-se esse vocabulário, entre outros presentes no PictoD (1995), um dos seus desajustes quanto à escolha dos lemas.

No seu Front Matter (s. p.), a obra apresenta duas personagens (Pic e Pac), que estarão presentes na maioria das figuras, assim como oferece uma introdução que afirma que esta obra está pensada para os leitores dos primeiros anos com a intenção de que eles conheçam palavras e seus significados com o apoio das imagens. Esse esclarecimento faz com que esse Front Matter cumpra com o requisito de especificar para que e para quem o material está destinado.

De acordo com as aclarações presentes no Front Matter do PictoD (1995), essa obra se divide em duas organizações macroestruturais: Vocabulario visual e Diccionario. A primeira seção (Vocabulário Visual) organiza-se por temas e a segunda (Diccionario) por progressão alfabética. Na seção organizada por temas, há uma representação dos lemas por imagens; na segunda, conta-se com definições de até sete linhas para cada lema. Além disso, há, no Front Matter, um índice que indica as páginas de cada tema da primeira organização.

Contabilizando as duas organizações macroestruturais da obra, o PictoD (1995) possui mais de 140 páginas. Torna-se importante mencionar também que a obra não conta com 
nenhum tipo de CD-ROM ou recurso auditivo, o que seria uma solução para dicionários pensados para crianças, visto que esse público-alvo já possui as destrezas de compreensão auditiva e expressão oral desenvolvidas, podendo, assim, buscar um dicionário com a finalidade de averiguar como "se diz" cada palavra lematizada.

Pode-se afirmar que, em função do seu número de páginas e da grande quantidade de lemas, a obra torna-se de difícil manuseio para o usuário. Primeiramente, deve-se considerar que são mais de 140 páginas para manuseio de uma criança de seis anos. Em seguida, pode-se pensar que a seção com definições de até sete linhas e lemas organizados alfabeticamente tornase praticamente irrelevante - ou ao menos de difícil compreensão - quando o educando ainda não está alfabetizado.

No índice da seção Vocabulario visual, encontram-se falhas organizacionais, pois alguns lemas não se encontram em seções de campos léxicos que podem interessar e fazer parte do contexto do usuário. Um exemplo é o lema tijera [tesoura], que é encontrado somente na seção sobre plantas, no subtítulo las herramientas de jardín - contexto que não faz parte dos potenciais consulentes deste dicionário, visto que, encontrando-se na posição de estudante, que recebe (juntamente com os pais, evidentemente) uma lista de materiais escolares que devem ser levados para a escola, o aluno muito possivelmente procuraria tijera na seção sobre material escolar, porquanto é nesse contexto que a criança desta idade utiliza esse instrumento.

Sobre a representação das figuras deste dicionário, acredita-se que essas imagens não poderiam ser utilizadas atualmente pelas crianças devido ao problema da temporalidade, já que as representações são de 1995, ano em que a obra foi lançada. O lema ordenador [computador] e o lema equipo de sonido [aparelho de som] que são representados, por exemplo, destoam muito do que os alunos hoje conhecem, conforme podemos ver na Figura 01 que segue:

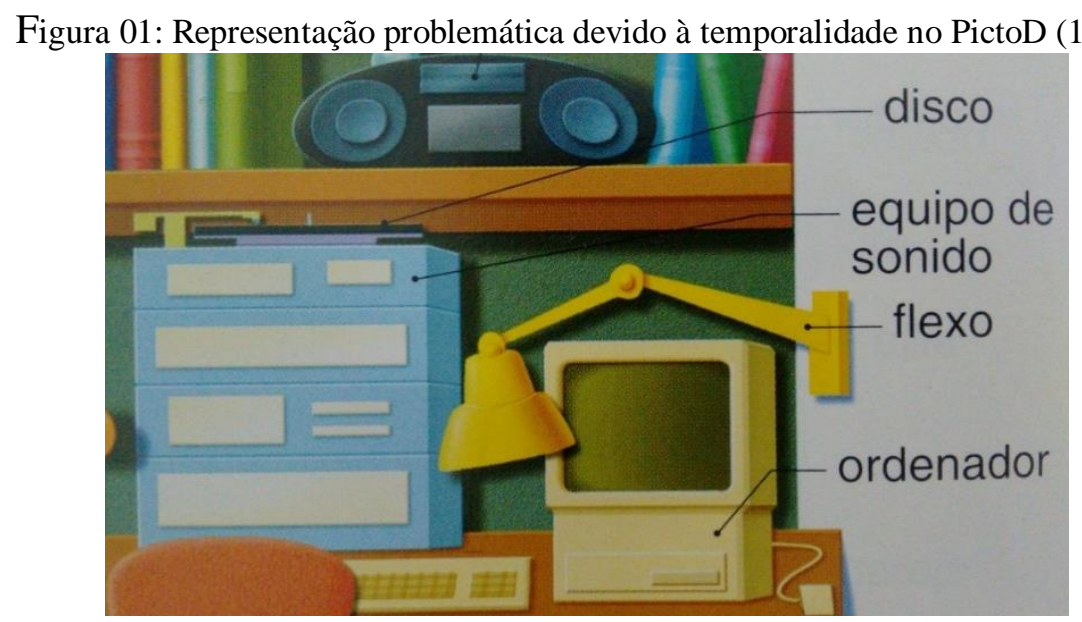


FONTE: Diccionario em imágenes Pictodiccionario (1995, p. 16).

Um fator positivo deste dicionário e que facilita o momento da consulta é o fato de alguns lemas aparecerem ao mesmo tempo em seções diferentes. Um exemplo é televisor [televisão], que aparece tanto na seção de aparatos electrónicos quanto na seção el salón. Dessa forma, o aluno pode realizar a consulta de acordo com seus próprios conhecimentos de mundo. Para o aluno A é possível que a busca faça mais sentido em determinada seção, enquanto o aluno B pode associar o mesmo lema a outro campo/seção que para ele tenha maior conexão. Ambos terão acesso ao lema, ainda que partam de diferentes caminhos. De acordo com Freire (1989), faz-se importante "respeitar os níveis de compreensão que os educandos - não importa quem sejam - estão tendo da sua própria realidade" (p. 17).

Ainda a respeito dos problemas de representação encontrados nas imagens desta obra, faz-se necessário mencionar que nela são representados verbos. Sendo verbo uma ação, conforme já mencionado, não se pode representá-lo integralmente com uma figura estática. Para exemplificar, é possível citar o verbo morir [morrer] (s.v.), que é representado com a Figura 02 que segue:

Figura 02: Representação problemática dos verbos no PictoD (1995).

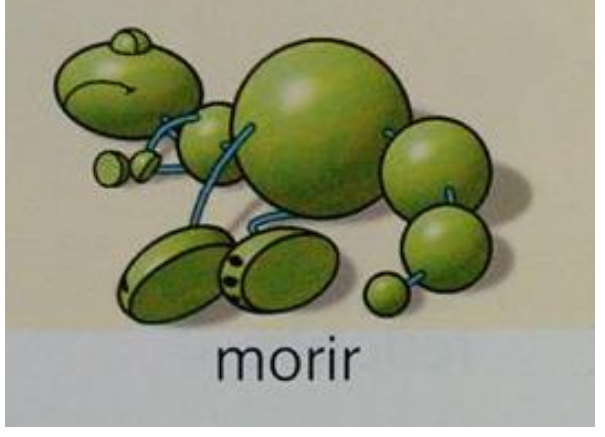

FONTE: Diccionario en imágenes Pictodiccionario (1995, s. v.).

Cabe questionar, nesse caso, como uma criança poderá entender que morir significa "morrer", visto que, de acordo com a representação pela imagem estática, pode-se entender que o animal está dormindo, cochilando ou desmaiado, por exemplo.

Também cabe refletir sobre a representação do verbo desnudarse [desvestir-se] (s.v), na qual a criança pode ter dificuldades de entender, sem uma representação com movimentos, se a personagem está colocando ou retirando as roupas, conforme a substituição ostensiva que segue na Figura 03:

Figura 03: Representação problemática do verbo desnudarse no PictoD (1995). 


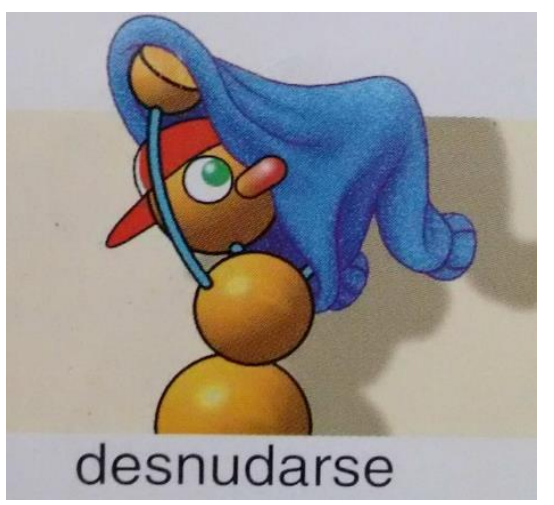

FONTE: Diccionario en imágenes Pictodiccionario (1995, s.v.).

\subsection{Análise 2: Dicionário por Imagens Brasileiro Espanhol (2001)}

Analisando a macroestrutura quantitativa do Dicionário por imagens Brasileiro Espanhol (doravante DIBE (2001)), encontra-se, na sua macroestrutura, 47 lemas em comum às palavras do quadro do léxico do livro didático analisado. No total, essa obra possui mais de 500 lemas organizados por temas. Assim como na análise anterior, grande parte dos lemas deste dicionário - mais de 400 lemas - não fazem parte do léxico que pertence, conforme o quadro do livro, a este nível do curso de espanhol para crianças. Tal fato permite concluir que, nesta obra, também há um inchaço macroestrutural.

A macroestrutura qualitativa dessa obra tampouco apresenta-se eficiente, porquanto não é encontrado, neste dicionário, parte do léxico presente no quadro macroestrutural elaborado, como o vocabulário do corpo humano, família e profissões, por exemplo - presentes em três das nove unidades do livro didático analisado; além disso, foram encontrados diversos lemas que não fazem parte do cotidiano infantil, como espécies muito específicas de pássaros ou tipos de plantas (vide sobre o ensino, de acordo com os PCN, de fauna e flora para esse público na análise anterior), - como cardo, jacinto, anêmona, gerânio (exemplos de plantas representadas no dicionário em questão) ou pega, melro (pássaros representados).

Sobre o índice (p. 128) e apresentação do dicionário, ou seja, o Front Matter (s. p.), pode-se afirmar que ele cumpre com os requisitos de informar para que e para quem o material se destina: "para auxiliar crianças nos seus primeiros passos na língua espanhola a desenvolver o vocabulário" (s.p.). A respeito das orientações de uso, este dicionário apenas apresenta um índice com as páginas organizadas por temas, não deixando claro como a obra deve ser utilizada. A organização do índice por temas, inclusive, é falha. Pode-se realizar tal afirmação ao se fazer a procura do vocabulário de material escolar, por exemplo, já que, apesar de haver 
uma seção no índice somente para materiais escolares (seção “objetos escolares"), nela não se encontram itens básicos, como bolígrafo [caneta] e pegamento [cola], por exemplo, que são objetos muito utilizados por crianças dessa idade, visto que esses materiais são solicitados nas listas de materiais que os alunos devem levar à escola. Outro item que seria importante estar nessa seção é mochila [mochila], que está presente no dicionário, porém se encontra na seção “os passatempos”, mais de vinte páginas e quatro seções após a seção “objetos escolares”. O mesmo ocorre com tijera [tesoura], que não é encontrada na seção de objetos escolares, mas sim na seção "a costura". Sabe-se novamente que, por serem materiais solicitados na escola e fazerem parte do cotidiano deste público, mais sentido faria, para a criança, procurar esse objeto nos materiais escolares. Outro lema importante que deveria estar nessa seção é libro [livro], que aparece, de acordo com o índice, na seção “o banheiro”. Isso dificulta imensamente a busca do usuário e torna o material ineficiente. Outro exemplo é o lema flores [flores], que aparece entre as seções descritas no índice como itens de "o banheiro" e "os brinquedos", ao invés de aparecer na seção "as flores". Apesar de existir uma parte do dicionário apenas para flores, em que encontramos diferentes tipos de flores (como clavel, petúnia, tulipán), o lema flor/flores não pode ser encontrado nessa parte.

Após analisar quais e quantas das palavras que se encontram no livro didático direcionado a crianças de seis anos estão representadas no DIBE (2001), pode-se concluir que, por um lado, é possível que a criança encontre o que procura para sanar as dúvidas que surgem ao longo dessa etapa do curso; por outro lado, ela pode ter muitas dificuldades ao localizar tais palavras em função da organização e falta de instruções de uso do seu Front Matter, além dos problemas macroestruturais mencionados nos parágrafos anteriores.

\subsection{Análise 3: Ouvir, Brincar e Aprender: Primeiras Palavras em Espanhol (2016)}

Encontram-se, na macroestrutura do dicionário Ouvir, brincar e aprender: Primeiras palavras em espanhol (2016) (doravante PrimPal (2016)), 36 lemas em comum com as palavras do quadro do léxico do livro didático. Esse dicionário possui, no total, 128 lemas organizados por temas e apresentados por substituição ostensiva (representação por imagens). Além da representação por imagem e escrita, PrimPal (2016) possui a emissão de sons para ver como se diz cada palavra, o que pode ser considerado um excelente recurso neste contexto onde os alunos estão começando seu processo de alfabetização. 
O Front Matter (s. p.) do PrimPal (2016) claramente explicita para quem e para que o material foi elaborado: para crianças acima de três anos conhecerem e aprenderem a falar palavras em espanhol a partir dos cartões sonoros. Além disso, cumpre com o requisito de especificar a forma de uso (que serve como o manual de instruções do material) oferecendo instruções simples em apenas 3 passos, conforme podemos ver na Figura 04 abaixo:

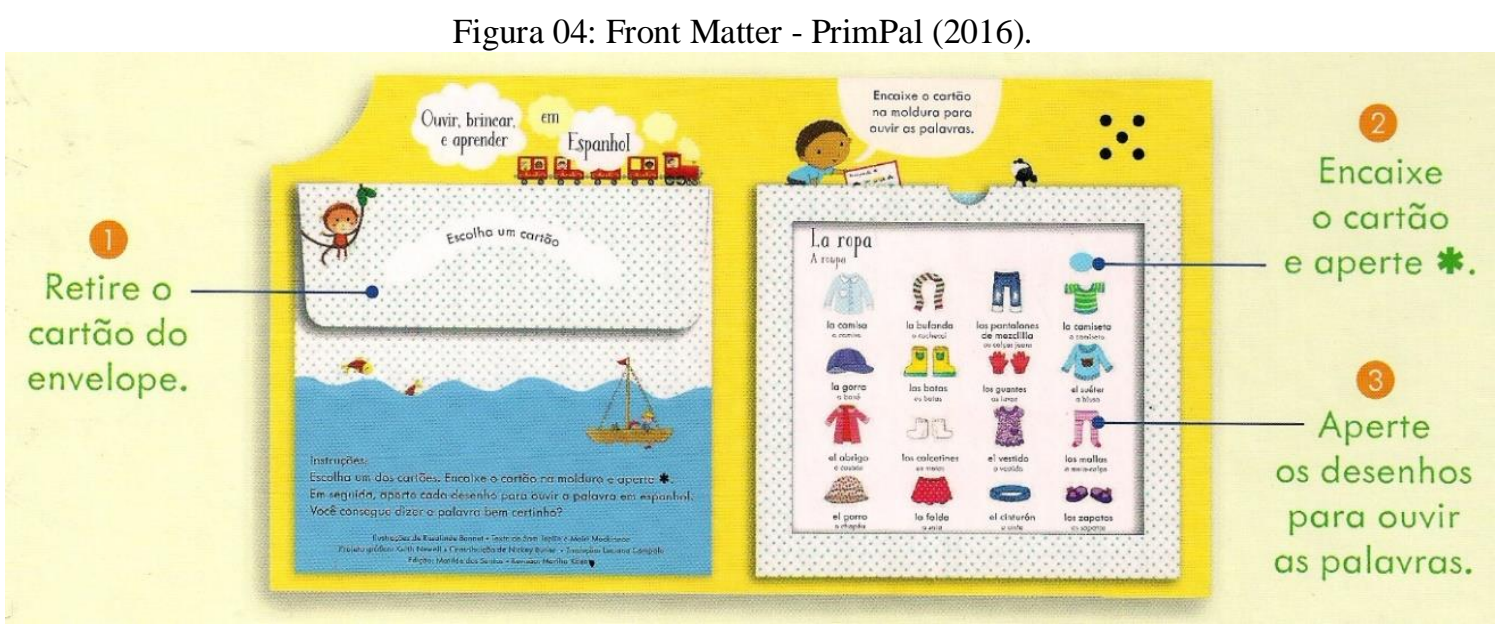

FONTE: Ouvir, brincar e aprender. Primeiras palavras em espanhol (2016, s.p.)

Ainda que o dicionário em questão não apresente um índice por não conter paginações, sua organização se dá em oito fichas fáceis de manusear no momento da pesquisa do aluno, promovendo uma interação com o material como um todo, já que o educando pode ver todas as fichas consecutivamente ou ao mesmo tempo - o que não ocorre em um material por páginas, por exemplo.

As fichas do PrimPal (2016) se organizam em campos léxicos bem definidos, que se dividem nos seguintes tópicos: La comida, En la granja, Vamos a dormir, Los animales, De acá para allá, En la casa, Mi cuerpo y La ropa. Cada ficha possui dezesseis itens, todos relacionados ao título da mesma. Não se encontra, nas fichas, nenhuma palavra deslocada que ficaria mais adequada em fichas de outro campo léxico. A ficha La comida, por exemplo, contém imagens das seguintes palavras: el pastel, el helado, el plátano, el sándwich, los huevos, la naranja, el pan, la ensalada, el jugo, la pasta, el chocolate, la leche, el queso, la mantequilla, la manzana, el yogurt.

Outra vantagem percebida no material é que as fichas estão organizadas por cores, o que facilita sua identificação para a criança. Há, no dicionário, um espaço bem definido para encaixar as fichas. A criança deve colocar cada ficha nesse espaço para ver e escutar como se pronunciam as palavras, conforme explica a ilustração das orientações. Ao colocar uma das 
fichas no molde do dicionário, o educando conseguirá ver, de forma panorâmica, todas as figuras que lhe interessam do campo léxico dessa ficha. Pensando no desenvolvimento da motricidade fina de uma criança desta idade, pode-se dizer que essa maneira de organizar um dicionário para esse público é mais eficiente que uma organização por páginas, visto que desde cedo as crianças possuem jogos de encaixes e blocos montáveis que estimulam essa capacidade. De acordo com testes e análises realizados por Rosa Neto (2002, apud SILVEIRA; GOBBI; CAETANO; ROSSI; CANDIDO; 2005), no que tange a motricidade fina, uma criança já é capaz de empilhar cubos aos 2 anos de idade e colocar uma linha na agulha aos 4. Essa habilidade de encaixe coincide, portanto, com o estágio em que a criança se encontra.

\section{Conclusões}

Ao realizar uma avaliação de dicionários ilustrados para o ensino de espanhol como língua estrangeira para crianças brasileiras dos primeiros anos do Ensino Fundamental, auxiliase e facilita-se seu uso aos educadores, que muitas vezes carecem de condições favoráveis para realizarem sozinhos essa tarefa - seja pela falta de incentivos e instruções para uma análise que envolva questões sobre o ensino-aprendizagem de crianças, seja pela falta de tempo para a realização das análises em si em meio a tantas tarefas de um educador infantil. Há também que considerar, neste caso, que muitos profissionais da educação não são preparados para ensinar línguas estrangeiras ao público infantil pelo simples fato de que isso exige do educador uma formação interdisciplinar que vai além do conhecimento do idioma. A necessidade dessa interdisciplinaridade na formação do professor para crianças fica evidente a partir de todas as características já mencionadas desse público-alvo, evidenciando-se que o ensino de crianças é uma tarefa que exige conhecimento das características cognitivas, afetivas e psicomotoras dessa idade.

Outro ponto relevante é como são selecionados os dicionários escolares para esse público infantil. Haja vista que não há nenhuma metodologia definida para que se possam realizar análises de dicionários, pode-se concluir que a seleção desse material não é fundamentada. Dessa forma, é correto afirmar que ter uma metodologia para um padrão de análise e, a partir disso, uma indicação de dicionários adequados ao público, facilita na hora de escolher qual material será levado para a sala de aula.

Percebeu-se, ao longo das pesquisas e análises realizadas aqui, que algumas classes de palavras não podem ser representadas eficientemente nos moldes de dicionários aqui avaliados. 
São necessários, ainda, mais estudos que averiguem a prototipicidade das figuras dos dicionários ilustrados e verifiquem em quais condições a substituição ostensiva de algumas classes de palavras torna-se eficiente. Cabe perguntar, por exemplo, se haveria melhores resultados em dicionários digitais, contudo não se pode fazer muitas afirmações a respeito da representação dessas classes de palavras até o momento.

A respeito do modelo metodológico criado a partir do léxico de um livro didático (que serviu como teste para as análises realizadas), considera-se necessário um aprimoramento dessa metodologia de análise macroestrutural para futuras avaliações de dicionários direcionados a esse público. Tendo em vista que não são muitos os livros didáticos de Espanhol que se direcionam especificamente a crianças de seis anos, considera-se perfeitamente possível, para o futuro, realizar um levantamento do léxico em totalidade ou em grande parte dos livros didáticos disponíveis no mercado editorial para a elaboração de um quadro-base que sirva com um corpus eficiente de avaliação macroestrutural de um dicionário infantil ilustrado para o ensino de espanhol para crianças de seis anos.

Afortunadamente, pode-se notar que houve, entre os dicionários analisados neste trabalho, uma melhoria e maior adequação nos dicionários publicados mais recentemente. É necessário, no entanto, que se ampliem os estudos das capacidades cognitivas, psicomotoras e de outras áreas que tangem o ensino-aprendizado para crianças para que se possam realizam análises com um maior embasamento. Finalmente, pode-se concluir que se torna perfeitamente possível desenhar um dicionário com uma macroestrutura adequada ao público de seis anos de idade a partir da criação de uma metodologia de análise elaborada com corpus gerado a partir de uma quantidade significativa de livros didáticos direcionados ao público.

\section{Referências}

DIBE. BEAUMONT, E. Dicionário por imagens brasileiro espanhol. 1. ed. Paris: PartenairesLivres, 2001.

BIDERMAN, M. T. C. Os Dicionários na Contemporaneidade: Arquitetura, Métodos e Técnicas. In: ISQUERDO, A. N.; OLIVEIRA, A. M. P. P. de O. (Org.) As Ciências do Léxico: Lexicologia, lexicografia e terminologia. Campo Grande: Editora UFMS, vol. I, 1998, p. 129142.

BORBA, L, C.; BUGUEÑO MIRANDA, F. Análise de cinco dicionários semasiológicos de língua espanhola: a correlação entre o front Matter e a Macro e Microestrutura. Extensio. Florianópolis, v. 9, 2012. 
BRASIL, LDB. Lei de Diretrizes e Bases da Educação Nacional, nº 9.394, de 1996.

PCN. BRASIL, Ministério da Educação, Secretaria de Educação Básica. Parâmetros curriculares nacionais: ciências naturais. Brasília: MEC/SEF, 1997. 136p. Disponível em: <http://portal.mec.gov.br/seb/arquivos/pdf/livro04.pdf> Acesso em 24 de outubro de 2017.

BREWSTER, J.; G. ELLIS \& D. GIRARD. The primary english teacher's guide - new edition. London: Penguin, 2002.

BUGUEÑO MIRANDA, F. O que o professor deve saber sobre a nominata do dicionário de língua. Língua \& Literatura, Frederico Westphalen, v. 67, n. 1, p.17-31, jan. 2004-2005. Anual.

Balanço e perspectiva da lexicografia. Cadernos de Tradução. Florianópolis: UFSC, v. 32/2, p. $15-37,2013$.

. Resenha crítica da obra Le Robert Junior illustré. Nouvelle édition. Paris: Le Robert, 2013, 1484 pp. Diacrítica, vol.30, nº.1, Braga, 2016.

BUGUEÑO MIRANDA, F.; FARIAS, V. S. O ensino de português e os dicionários escolares: um segmento informativo da microestrutura para fins de produção textual. Polifonia. Cuiabá, MT: Editora Universitária, V. I, p. 1 - 14. 2008.

CamDic. Cambridge Free English Dictionary and Thesaurus. Cambridge: Cambridge University Press, 2017. Disponível em: <https://dictionary.cambridge.org/dictionary/>. Acesso em: 26 out. 2017.

CAMERON, L. 2001. Teaching English to Young Learners. Cambridge: Cambridge University Press.

CHAGURI, J. de P. "O jogo como recurso lúdico no ensino de espanhol para crianças”. In V. C. P. Lugli; O. L. Nadin (orgs.). Espanhol como língua estrangeira: reflexões teóricas e propostas didáticas. 1ed. Campinas, SP: Mercado de Letras, 2013.

ELLIS, G. 2004. Developing Intercultural Competence with Children in the English Language Class. Thresholds. Disponível em http://w.w.w.counterpointonline.org/doclibrary/british_council/download /179/Thresholds-1-Gail-Ellis.pdf. Acesso em 05 de outubro de 2018.

FREIRE, P. A importância do ato de ler: em três artigos que se completam. São Paulo: Autores Associados: Cortez, 1989. 23 ${ }^{\text {a }} \mathrm{Ed}$.

GOUWS, R. Types of Articles, their Structure and Different Types of Lemmata. Van Sterkenburg, P. A practical guide to lexicography. Amsterdam: John Benjamins, 2003, p. 3443

LEFFA, V. J.; IRALA, V. B. O ensino de outra(s) língua(s) na contemporaneidade: questões conceituais e metodológicas. In: Vilson J. LEFFA; Valesca B. IRALA. (Orgs.). Uma 
espiadinha na sala de aula: ensinando línguas adicionais no Brasil. Pelotas: Educat, 2014, p. 21-48.

LÓPEZ, B. R.; MÉNDEZ, R. V. Models of Teaching Foreing Languages to Young Children. Didáctica (Lengua y Literatura). Madrid. Vol. 16. Pág. 163-175. 2004.

PrimPal. MACKINNON, M.; TAPLIN, S. Primeiras palavras em espanhol: Ouvir, brincar e aprender. Berberi: Usborn, 2016.

MCER. Marco común europeo de referencia para las lenguas: aprendizaje, enseñanza, evaluación. España: Ministerio de Educación, Cultura y Deporte, 2002. 263p. Disponível em: $<$ http://cvc.cervantes.es/ensenanza/biblioteca_ele/marco/cvc_mer.pdf $>$. Acesso em: 19 de agosto de 2017.

PictoD. Pictodiccionario: diccionario en imágenes. Madri: Santillana, 1995.

REAL ACADEMIA ESPAÑOLA: Banco de datos (CREA) [en línea]. Corpus de referencia del español actual. Disponível em: <http://www.rae.es>. Acesso em: 26 de outubro de 2017.

DLTApL. RICHARDS, J. C; SCHMIDT, R. W. Longman dictionary of language teaching and applied linguistics. 3th Ed. Pearson Education, 2002. Disponível em: $<$ https://archive.org/stream/DictionaryOfLanguageTeachingAndAppliedLinguistics/Dictionar y\%20of\%20Language \%20Teaching\%20and\%20Applied\%20Linguistics\#page/n303>. Acesso em: 12 set. 2018.

SILVEIRA, C. R. A.; GOBBI, L. T. B.; CAETANO, M. J. D.; ROSSI, A. C. S.; CANDIDO, R. P.; Avaliação motora de pré-escolares: relações entre idade motora e idade cronológica. Revista Digital, Buenos Aires, $\mathrm{N}^{\circ}$ 83. 2005. Disponível em: <http://www.efdeportes.com/efd83/avalia.htm>. Acesso em 18 out. 2018.

ROCHA, C. H.; TONELLI, J. R. A.; SILVA, K. A. Língua estrangeira para crianças: Ensinoaprendizagem e formação docente / Cláudia Hilsdorf Rocha, Juliana Reichert Assunção Tonelli, Kleber Aparecido da Silva (Orgs.). Campinas, SP: Pontes Editores, 2010.

ROCHA, C. H. Provisões para Ensinar LE no Ensino Fundamental de $1^{a}$ a $4^{a}$ Séries: dos Parâmetros Oficiais e Objetivos dos Agentes. Dissertação de Mestrado. Campinas, IEL/Unicamp. 2006(a).

ROCHA, C. H. O ensino de línguas para crianças no contexto educacional brasileiro: breves reflexões e possíveis provisões. Delta, São Paulo, 2007, vol. 23, n. 2.

RUIZ, A. I. V. Dar clase a niños no es un juego de niños. Berlim, 2014. Disponível em: $<$ https://www.encuentro-pratico.com/berlin/pdf/ensenar_espanol_ninos.pdf>. Acesso em agosto de 2018.

VYGOTSKY, L. S. A formação social da mente. 4. ed. São Paulo: Martins Fontes, 1991. 
Recebido em 29 de outubro de 2018. Aceito em 04 de janeiro de 2019. 